\title{
FLOOD RISK ASSESSMENT OF RIVER KABUL AND SWAT CATCHMENT AREA: DISTRICT CHARSADDA, PAKISTAN.
}

\author{
T. Bibi ${ }^{1, *}$, F. Nawaz ${ }^{2, *}$, A. Abdul Rahman ${ }^{1}$, K. Azahari Razak ${ }^{3}$, A. Latif ${ }^{4}$ \\ 1,* 3D GIS Lab,Faculty of Built Environment and Surveying, Universiti Teknologi Malaysia, Skudai 81310, Johor, Malaysia - \\ tehmina_khan79pk@ hotmail.com, alias.fksg@gmail.com \\ 2,* Network of Disaster Management Practitioners (Pvt) Ltd, Islamabad, Pakistan. - falak@ pakndmp.com \\ ${ }^{3}$ UTM RAZAK School of Engineering and Advanced Technology, Universiti Teknologi Malaysia, Malaysia - khamarrul.kl@utm.my \\ ${ }^{4}$ Dept. of Education, Azad Jammu and Kashmir, Muzaffarabad. - adnan_ajk@hotmail.com
}

KEY WORDS: Hazard, Vulnerability, Risk, Geographical information system (GIS), Remote sensing (RS), Disaster risk reduction (DRR), Participatory rural appraisal (PRA) tools, Weighted overlay

\begin{abstract}
:
Pakistan is prone to natural hazards including floods, in particular, affecting millions of people each year across the country. Patterns from recent years suggest the intensity of flooding are increasing and may continue more aggressively during the coming years because of increased magnitude of the monsoon rains and identified climatic changes in the region. Mapping of flood hazard is essential for planning and mitigation purpose. However, only flood hazard mapping is not sufficient to assess the magnitude of risk to lives and property. Risk mapping is an integral part of pre and post disaster management. Furthermore, the Earth Observation (EO) data could be helpful to update flood risk maps time to time by covering many aspects e.g. population concentration areas, critical infrastructure and commercial areas, to enhance the preparedness planning and mitigation measure against risk of flood. Pakistan has experienced the devastating flood in 2010 due to unexpected heavy rainfall in the monsoon season with enormous losses to property lives and infrastructure in several districts. The Union council Agra, District Charsadda was among the affected most districts by riverine and flash floods. Additionally, growing population in flood plains is another threat to the district. However, to cope with this situation there is immense need to detect risk index to prevent further damages caused by such floods. This study aims to prepare the hazard, vulnerability and risk index for River Kabul and Swat catchment area of union council Agra, Charsadda. the flood risk was identified, and risk index maps were prepared by executing a methodology for assessing risk, based on the physical exposure of the flood hazard, vulnerability of people, and the exposure of critical assets to flood water. Explicitly, spatial flood risk index maps were produced with the help of analytical spatial modeling by considering the areas exposed to flood hazard, morphological characteristics and socio-economic indicators. The produced flood risk maps were verified through visual examination through 3D city flood maps. Results illustrate that the areas of higher flood risk overlapped with the areas of high flood hazard along with high population density and socio-economic exposure to vulnerability.
\end{abstract}

\section{INTRODUCTION}

\subsection{Background of the study}

Natural hazards are the events, occurred naturally due to some physical or climatic changes, but when it interacts with the communities and caused damage to live and property, then it is known as natural disasters. Several phenomenon's, such as landslides, earthquakes, volcanic eruptions, heat waves, tsunamis, storms, floods, tornadoes, droughts and many more (Alcántara-Ayala, 2015; Strupler et al.,2018). The impact of disasters is increasing rapidly since last decade of nineteenth century particularly in developing countries due to low resilience. Floods are frequent natural disaster all over the world which could easily cause serious threat to human lives and properties.it is one of the most serious and devastating natural hazard as most of the population in the world prefer to live along river basin or valleys. Therefore, the effects of flooding are always severe for both urban as well as rural communities. The South Asian countries are severely exposed to flood events firstly, due to the impacts of climate changes and secondly, because of rapidly growing population along water bodies. Moreover, the severity of floods increased much more as compare to past in last few decades for the reason of climate changes and urbanization.

Some of the key causes of flood occurrence are change in climatic conditions, urbanization, inefficient and inadequate drainage network, deforestation, and development along banks of the rivers (Adeoye et al. 2009). Floods are the most notorious natural hazards which disturb the life and damage the property on a quite wide scale (Ahmed et al. 2011). Seasonal floods are very common in Pakistan especially in monsoon season, but the century's worst flood experienced in 2010. It was claimed that almost 20.2 million people were influenced and around 1985 lives were lost in the flood of 2010. Approximately 2.1 million houses and 515 health facilities were damaged while nearly 2.4 million hectares of agricultural land was damaged (NDMA, 2010). The Disease Early Warning System (DEWS) reported more than 37 million cases of casualties within one year after the floods including more or less $23 \%$ critical respiratory infection, $11 \%$ complaints of skin diseases while acute

* tehmina_khan79pk@hotmail.com

* falak@pakndmp.com 
diarrhoea were reported $9 \%$ cases and $6 \%$ cases were diagnosed as suspected malaria (WHO, 2011).

Being an agricultural country Pakistan has one of the greatest and planned river/ canal system but unfortunately due to negligence to sustain the system, millions of people every affected by floods living in the catchment areas of these rivers and canals in the major part of the country. One of the provinces of Pakistan, Khyber Pakhtunkhwa (KP) flooding is a regular hazard due to the presence of major rivers such as river swat and Kabul and several tributaries (Riaz, 2010). KP was the worst effected province of Pakistan in by flood in 2010 caused due to heavy rain in monsoon season. Additionally, the 2010 flood broke all the existing records not only for rainfall and discharge but also damage to life and property. This alerting situation revels that it may continue in coming years more violently as in 2010 . The key factor of flooding was the higher intensity of rainfall due to certain known climatic changes in this region. However, considering this disastrous situation it is crucial to give attention towards flood risk management.

District Charsadda in KP is always endangered to risks from floods because of river Kabul and river Swat. In 2010 the approximately 200-280 millimeters rainfall was recorded in surrounding areas of Peshawar, Charsadda, and Nowshera and river Kabul was detected as very high flood stage $(221,000$ Cusecs). The district is prone to both flash floods as well as riverine floods. Furthermore, intensive agriculture in the district has resulted huge deposits in the river beds which decreased the water carrying ability of the rivers and repeated overflow has been experienced. Similarly, population stress along drainage system also played vital role. All these factors contributed to force the rivers and tributaries to overflow from the watercourse.

The study consists hazard mapping and risk assessment of union council (UC) Agra, district Charsadda, Kp. Recommendations will be presented in this study aim at ensuring risk informed programming for supporting vulnerable communities exposed to climatic changes and weather-related hazards, particularly physical and social assets. This study will help in preventing the water, sanitation and hygiene related diseases faced by communities living in flood hazard prone areas.

\subsection{Flood Hazard Mapping and Risk Assessment}

Hazard maps are crucial to minimize the deadly effects of floods. It is considered as the first and foremost step of flood risk assessment (Haq, 2011; Houze et al., 2011). The effects of disaster on vulnerable areas could be minimized by preparing hazard maps (Hussain et al., 2010) as the vulnerability to geohazards including life and property damages are the major concerns of disaster preparedness. Moreover, these maps might be used as guide for development and construction around the flood overstressed areas (Khan, Iqbal and Yosufzai. 2011).

To reduce the impact of flood hazard in urban communities the risk assessment is crucial. While risk is the likelihood of some event expected to occur in future, which has a negative impact on the societies living in risk prone areas. Risk assessment is an organized investigative process which assist in detecting hazards, calculating the likelihood of their occurrence and condition-based consequences followed by comparing with some standards to decide the desirable action either to reduce the probabilities or to protect lives, assets and environment. Nevertheless, the Incompatibility amongst hazard and vulnerability is the major cause of risk (Ologunorisa and Abawua 2005). Disaster risk assessment must be done in a participatory manner by including the participation of insiders as well as outsiders involved in field for data collection, and simultaneously interpreting and analyzing the indications from numerous sources.

Numerous structural and non-structural measures are involved in an integrated flood risk management. Although, structural measures necessitate enormous funding, which is not practical for developing countries. Therefore, instead of adopting structural measures non-structural measures should considered to serve more productive measure in less cost. Moreover, nonstructural measures are applied in adequately in recent flood mitigation. Consequently, different non-structural measure including flood hazard mapping, hazard zoning, building codes, early warning system, flood insurance, emergency planning etc. took the place of conventional structural measures (Simonovic, 2002).

The Article comprises on five sections. Section one includes background of the study, flood situation in Pakistan and need of flood hazard mapping. Moreover, section two contains the physical, climatic and demographic information of study area. Consequently, Section three explains the detailed methodology used for this study and in section four results are discussed. Finally, section five encompasses the conclusion and recommendations of the study.

\section{STUDY AREA}

\subsection{Physical Setting}

Agra is a town and UC of District Charsadda in KP province of Pakistan. It is located at $34^{\circ} 6^{\prime} 54 \mathrm{~N} 71^{\circ} 41^{\prime} 51 \mathrm{E}$ and has an altitude of 273 metres ( 898 feet). The district is bounded by Mardan in the north, Mohmand agency in the west, and Nowshera in the south. The area is among one of the most fertile regions having mineral-rich soil (Osti, 2008) In Charsadda the UC Agra is located approximately eighteen kilometres from the provincial capital of Peshawar. It is traversed and bounded by two rivers and two tributaries called as Khialey and Jinday rivers. Two major roads Motorway on eastern side and G.T. Road on northwest side passing the UC Agra. Different tertiary roads located at upstream of Kabul and swat rivers providing the access to several villages and used as second line of defense in flooding season. Agra Payan-Gulabad and Jamat-Shabarha roads provide protected routs for evacuation during flood hazard.

\subsection{Physiography of the Rivers in Study Area}

Kabul and Swat Rivers mainly act as drainage outlet for the UC Agra. Kabul River emerges from the western mountains and upon entering the survey area divides into three creaks of braided channels called Shah Alam, Noguman and Sardaryab due to the decrease in the gradient. The Swat River, enters Charsadda at Abazai, flows from north to south and meets the Kabul River near Charsadda. Another small narrow river called as Jindai emerges from the northern mountains and flows into south, meets the Kabul River near Prang villag 


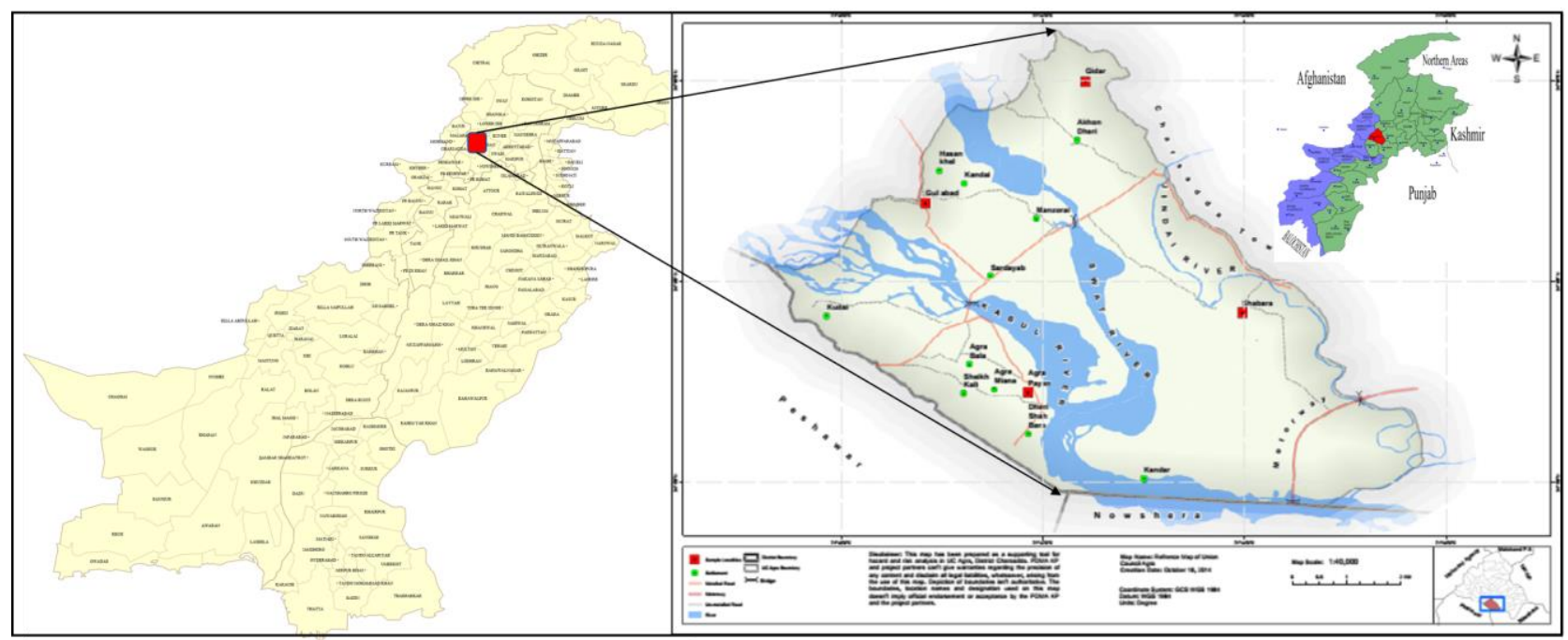

Figure 1. Location Map of Union council Agra

The discharge of both the rivers, which are mainly snow fed, are highly seasonal, increasing flow in spring season because of snowmelt. Both the rivers start rising in late February, reaching the highest discharge level in June and July when the snow melt water is supplemented by monsoon rains. Decline in flow discharge continues till end of October to January, interrupted by occasional floods due to irregular rains.

\subsection{Climatic Conditions}

UC Agra and its surroundings experienced very hot climate throughout the summer as well as extremely cold in winter season. It is generally influenced by the local steppe climate According to Köppen classification charsadda lies in BSh. And the climate varies from semi-arid to sub-humid, continental, and subtropical. May to September it is considered summer season while June is the dry and hottest month of the year usually in this month the temperature exceeds than $40^{\circ} \mathrm{C}$. Moreover, the monsoon season continues from July till September.

Additionally, these months are the hottest and highly humid months throughout the year. Highest amount of rainfall occurs due to monsoon and the western disturbances. The average rainfall differs from 300 to $625 \mathrm{~mm}$. Based on climatic data, the semi-arid zone has maximum rainfall in winter, while the subhumid zone has a maximum monsoon rainfall in summer.

\section{METHODOLOGY}

\subsection{Material and Methods}

Hazard, vulnerability and risk assessment procedure cover numerous technical and methodological approaches, including an evaluation of past and current researches and activities interrelated to hydrogeological hazards such as hydrological, meteorological, and topographical phenomena. For exposure, vulnerability and risk assessments; population, buildings, crops, transport and infrastructure parameters were considered. Through extensive consultation process with provincial and district level government line departments and non-government organizations and community stakeholders, the primary data were collected to analyze the historical hazards and disasters catalogue, elements of vulnerability and exposure and the geographical extent. Data gaps, alternative sources, verification of hazard assessments and delineation, elements of vulnerability estimation and coping capacity assessments have been completed during different field surveys through various participatory rural appraisal (PRA) tools.

The study was completed in four phases: a) hazard assessment; b) exposure/vulnerability assessment; c) risk assessment; and d) capacity assessment.

Hazard assessment: Identify, list down and describe the nature of hazards in terms of its recurrence, reasonability, location, possibility of early warning and general knowledge of the people about the hazard.

Vulnerability and exposure assessment: Identify what elements are at risk and why (refer to unsafe conditions, dynamic pressures and root causes).

Capacity assessment: What are people's coping strategies; what resources are still available; who has access and control over these resources?

Community's risk measurement: Understanding the people's perception of risk and their perception about the coping mechanism is extremely of immense importance. It plays key role while suggesting for the DRR measures o sustainable manner.

For detailed hazard and risk assessment of UC Agra, a GIS based methodology was used to assess the flood hazard, vulnerability and risk. The weighted overly method was used to calculate the hazard and risk zones along with buffer analysis. Furthermore, to prepare flood hazard and risk indexes 30-meter Aster Digital Elevation Model (DEM) was used. The final output products are composite hazard, exposure and risk maps with detail hazard and risk profile for UC Agra, District Chasadda. 


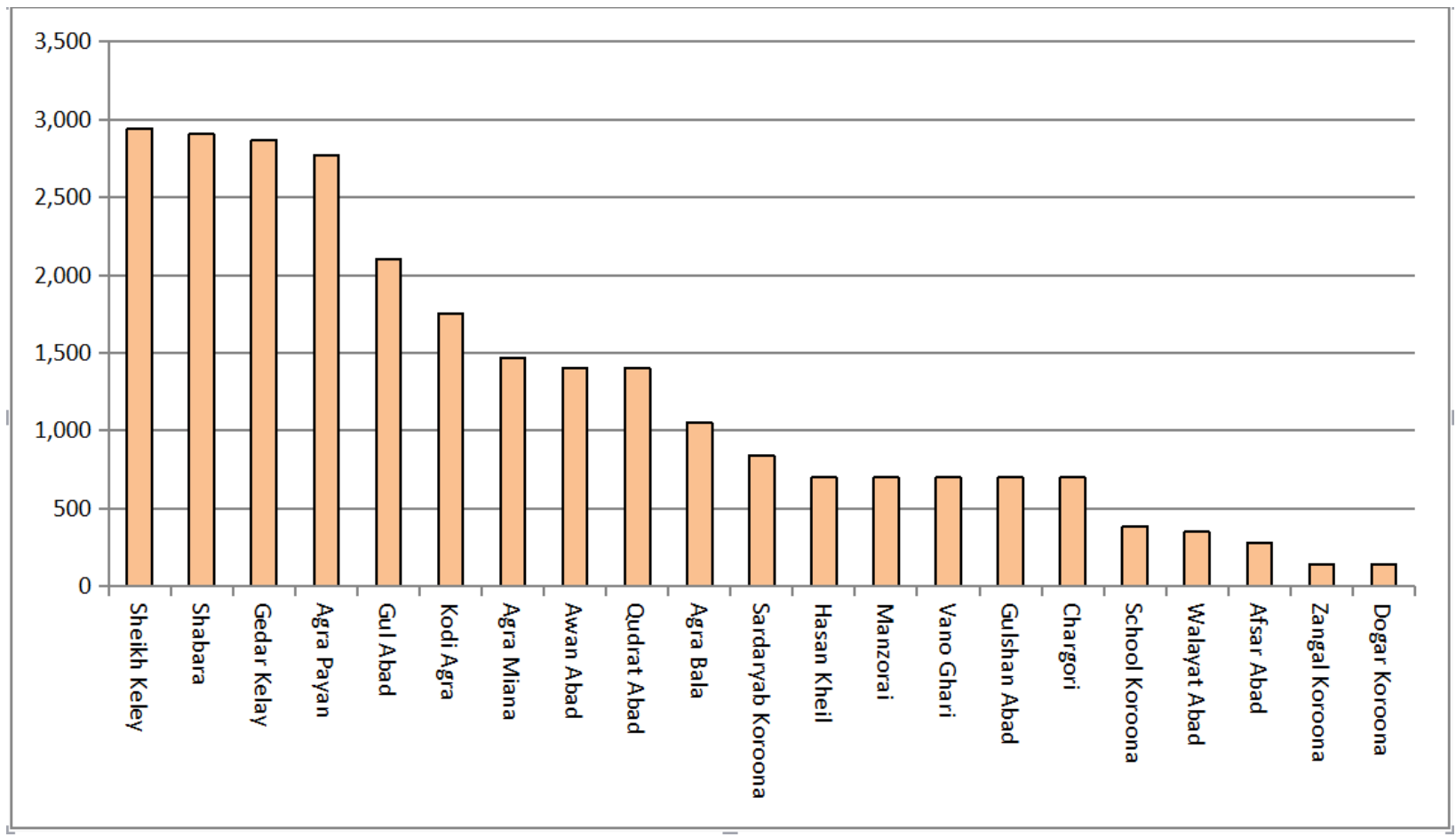

Figure 2. Population distribution of UC Agra (Source: Projected from District Census Report, 1998, District Charsadda and verified from LSO Nangyal, 2014)

The final risk assessment data and maps were compiled after thorough consultation, verification and adjustment. The conclusive results were then transferred into better visual interpretation models using different mapping techniques.

\subsection{Tools used for Hazard Assessment}

Intensive field surveys using PRA tools were conducted. Additionally, for social mapping, hazard mapping, historical profile, seasonal calendar, transect walk, direct observation the key informant interviews and focus group discussions (FGDs) were conducted and in the later stage analyzed through various techniques of GIS to get the maximum accurate results. Historical events data sources were utilized to collect data about past flood disasters, their damages and extent from relevant organizations including Pakistan Meteorological Department (PMD), Irrigation Department, University of Peshawar, SUPARCO and PDMA, KP. Based on available secondary sources, flood 2010 inundation map was prepared. secondary data was verified during field surveys through PRA tools. The model-based results were calibrated from these records.

\subsection{Tools used for Vulnerability Assessment}

Exposure as defined as people, property, crops and systems, or other elements present in flood hazard zones that are thereby subject to potential losses. These can be combined with the specific vulnerability \& fragility of the exposed elements to flood hazard to estimate the quantitative risks associated with that hazard in the area of interest. Exposure and vulnerability assessment is an intermediate stage of risk assessment, which links hazard assessment with human, physical and economical parameters under consideration for risk assessment. The analysis helps to identify what and how much of various elements in Agra UC are at risk of the flood hazard.
For the study, five percent of sample surveys of the projected Population Census Organization 1998 were utilized. Primary data about vulnerability, exposure was collected through FGD, Questionnaire survey, key informant and semi structured interview and other PRA tools e.g. transect walk etc. The same enumerators were involved in the data collection processes that were trained in the UC and village level workshops. Besides the primary sources, data from the District Census Report (DCR) of 1998 and LSO Nangyal (a local community organization) were used to compile information about socio-economic indicators. DCR of 1998 is the only authentic source available from government of Pakistan.

The composite exposure layers were calculated from the sum of weightages of exposure elements multiplying with different weightages, we mainly assumed population, buildings, crops, and essential infrastructures i.e. roads, schools and health facilities. The results were then cross checked with PRA (FGDs \& Questionnaire) results and historical events-based bench marks of flood 2010.

In this study, the elements exposed are considered mainly in four dimensions: i) Population; ii) crops and livestock; iii) physical assets including social infrastructure such as schools, hospitals, roads \& bridges.

3.3.1 Population: There is considerable variation among the 'social groups/age groups' within the range and severity of the hazards. Within the household, different age groups are exposed to the hazard differently. Unlike other dimensions of social pattern, the consideration of different age groups getting more importance in the country after the lesson learned from earthquake 2005 and 2010 flood disasters. 


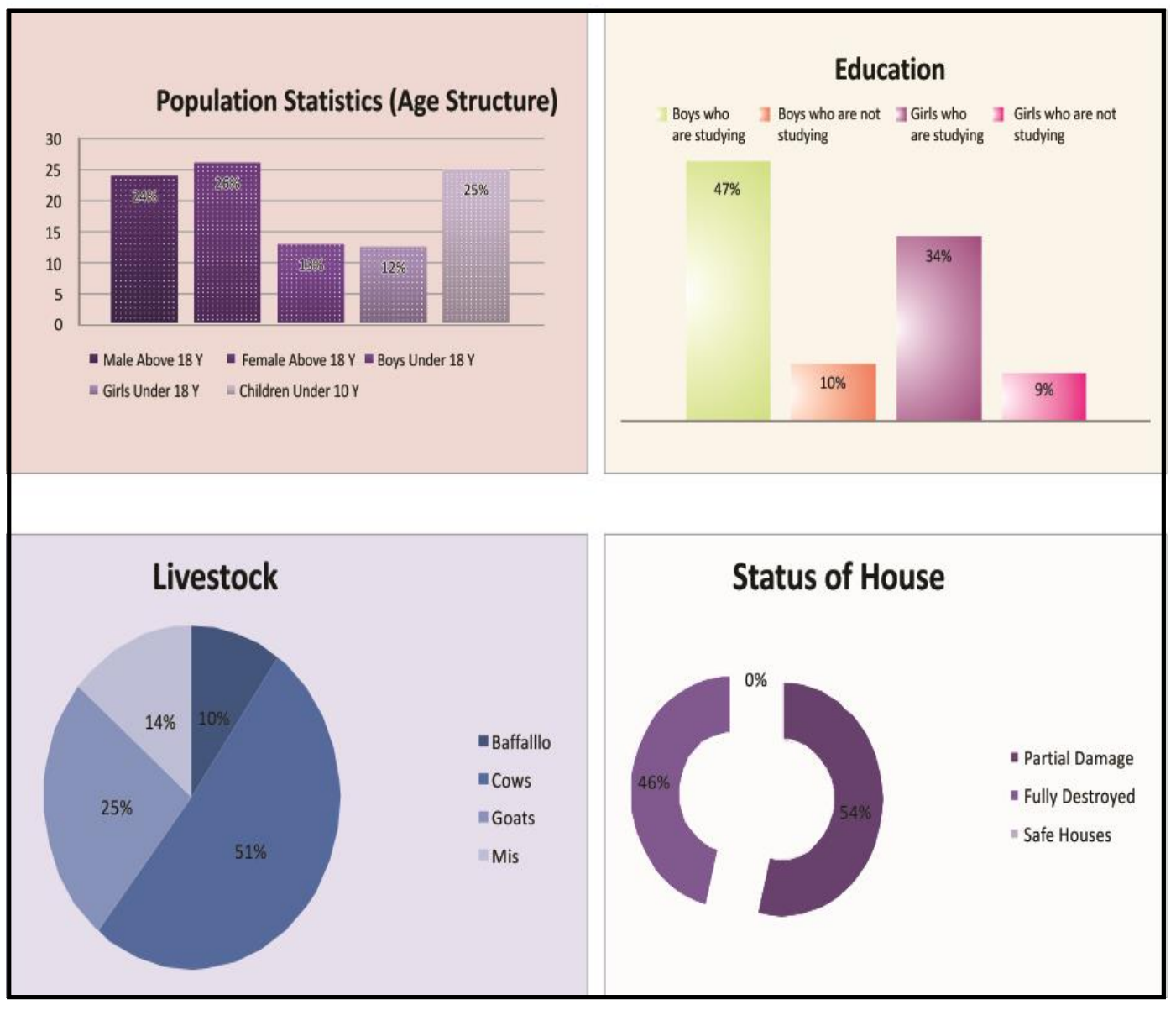

Figure 3. Physical and Social Profile of UC Agra village (Charsadda)

We learnt from these disasters that gender and age perspective made difference in the death toll and injuries, as children, women, special people and old age people are more vulnerable and can easily be affected during disasters. Table 3 and figure 14 shows the population characteristics of UC Agra.

In assessing the population vulnerability for the natural hazards in the district considering different parameters like Gender, wealth, education, influence in general while the two important parameters of age and ability, children and elderly people tend to be more vulnerable. They have less physical strength to survive in disasters and are often more susceptible to certain diseases. The elderly also often has declining vision and hearing. Children are frequently dependent on others for survival decisions. In the study, the children group considers those below the age of 15 years, and the elderly group as above 65 years.

3.3.2 Crops and Livestock: Floods and land erosion were considered for the assessment of vulnerabilities to crops. For this purpose, an assessment matrix was filled through focus group discussion during field visits. The impacts were assessed for the major cash and cereal crops and fruits grown in the UC like wheat, rice, maize, fodders, persimmon, grapes, apricot, peach, plum, vegetables and some other. Based on the secondary data, livestock species found in the region are buffalo, cow, goats and other domestic animals. Total number of livestock in UC Agra is 5,787.

3.3.3 Physical Assets: After human element, the most crucial elements are the shelters and the dwelling units found in an area. During any disaster, the loss of shelter is considered the most crucial loss. In assessing the natural hazard risk to housing units, the information about structural condition of units needs to be collected. According to the housing census of Pakistan 1998, the housing conditions has been categorized into threegroups, namely, i) katcha ${ }^{1}$ houses/structures likely to be severely damaged; ii) semi pacca ${ }^{2}$ houses and structures likely to be partially damaged, and iii) pacca dwelling units, generally resilient to damages. The required detail about buildings information are not available at the UC level, therefore, the Consultants conducted a sample survey of selected localities for classifying the building in different construction type categories and other relevant variable.

3.3.4 Physical and Social Infrastructure: Essential/critical facilities are the primary physical structures, technical facilities and systems that are socially, economically or operationally

\footnotetext{
${ }^{1}$ Katcha house: adobe walled house

${ }^{2}$ Pacca house: partly adobe walled and partly brick walled
} 
essential for the functioning of a society or community, both in routine circumstances and in the extreme circumstances of an emergency. These can be included as transport systems, schools, health facilities, livestock, electricity, water sanitation and communication systems, hospitals and clinics, centers for fire, police and public administration services etc. Figure 3 show some of the infrastructure in four selected villages.

\begin{tabular}{|l|l|}
\hline Essential facilities & Numbers \\
\hline Schools & 25 \\
\hline Hospitals & 3 \\
\hline Roads in KM & 75.7 \\
\hline Hand pumps & 2,398 \\
\hline Latrines & 3,205 \\
\hline
\end{tabular}

Table 1. Social and physical infrastructure in UC Agra Source: LSO Nangyal, UC Agra 2014

Having known the risk to these facilities, special consideration can be given when formulating disaster management plans. Further, a critical facility should not be in a high-risk area if possible. If a critical facility must be in a high-risk area, it should be provided a higher level of protection so that it can continue to function and provide services.

Exposure can be defined as people, property, crops and systems, or other elements present in flood hazard zones that are thereby subject to potential losses. These can be combined with the specific vulnerability \& fragility of the exposed elements to flood hazard to estimate the quantitative risks associated with that hazard in the area of interest. Exposure and vulnerability assessment is an intermediate stage of risk assessment, which links hazard assessment with human, physical and economical elements under consideration for risk assessment. The analysis helps to identify what and how much of various elements in Agra UC are at risk of the flood hazard. For this study, five percent sample surveys of the projected Population Census Organization 1998 were utilized. Primary data about vulnerability, exposure was collected through FGD, Questionnaire survey, key informant \& semi structured interview and other PRA tools e.g. transect walk etc.

Besides primary data, District Census Report (DCR) of 1998 and LSO (a local community organization) data was used to compile data about socio-economic indicators. DCR of 1998 is the only authentic source available from government of Pakistan. The census data of 1998 were projected to 2014;

projected data were crossed check during primary data collection. The data was to generate attribute data which transformed into GIS to get exposure, and vulnerability maps and layers. The data was overlaid on classified hazard maps at 3 different return periods $(10,30$ and above 100) to know the population, buildings, crops, transport and essential critical facilities etc. exposed to specific hazards.

\subsection{Techniques for exposure analysis through weighted overlay method}

The composite exposure layer was calculated from the sum of weightages of exposure elements multiplying with different weightages, we mainly assumed population, buildings, crops, and essential infrastructures i.e. roads, schools and health facilities. The results were then cross checked with PRA (FGDs \& Questionnaire) results and historical events-based bench mark i.e. Flood 2010. Map 15 shows the final map in the form of exposure map of UC Agra.

\subsection{Risk Assessment Tools}

Risk assessment is exploration and determining of the nature and extent of risk by analyzing potential hazards and evaluating existing conditions of vulnerability that together could potentially harm exposed people, property, services, livelihoods and the environment on which they depend. Risk is considered as function of hazard, exposure and vulnerability. The final stage in the study is the creation of classified risk map with three different return periods i.e. 10, 30 and 100 years along with detailed risk profile of the UC Agra.

A qualitative risk maps have been produced with the combination of hazard, exposure and vulnerability maps to get the final risk maps (Map 6-7). For this purpose, weightage and ranking criteria was adopted to get qualitative risk maps. Data was crossed checked with the community level hazard and risk maps developed during field surveys of each selected village.

The resulted risk maps developed by communities were crossed check with the computer-generated risk maps. The risk assessment includes major economic activities, building fragility, crop damages, critical infrastructure and other socioeconomic activities that can be affected by any future flooding. The data from questionnaires and the graphs, maps and tables were incorporated to estimate element at risk. The methods used are weighting, raster multiplication, raster sum, different spatial analysis operations in GIS packages.

The risk assessment profile at the UC and village level has also been developed through PRA tools in consultation with community validated with the computer-generated risk maps. By combining hazard layers with the exposure layers to generate the vulnerability zones as low/moderate and high through intersection overlay techniques. Village wise risk analysis is given in table 2 . The results were validated with data collected through field surveys. After validation, final risk and risk indexing has been done for the union council as shown in table and map below. Based on the classified risk maps, suitable site area for DRR interventions on 10, 30 and 100 flood return periods have been identified in Map 18-19. Such maps can be utilized at planning tools for future development intervention in the UC Agra.

\section{RESULTS}

The study capitalized on different techniques used for risk assessment on the basis of hazard assessment and flood return periods of 10,30 and 100 years. According to the risk assessment study, the total population exposed to 10 years return period of flooding was 26,290 with low vulnerability ranking. Out of 26,290 populations; 8,724 peoples were at risk to 30 years flood return period with moderate vulnerability ranking. Population at risk on 100 years return period was16,745 with high vulnerability ranking. Total 3,807 buildings with low vulnerability ranking for 10 years return period there were 1,446 buildings at risk to 30 years flood return period with moderate vulnerability ranking. While on 100 years return period 2,817 were at high risk in the study area. 


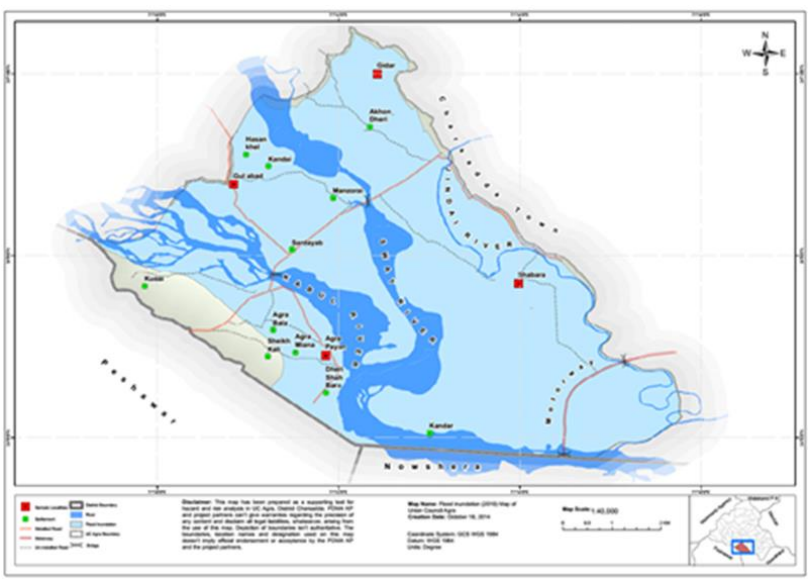

Figure 4. UC Agra - 2010 flood inundation map

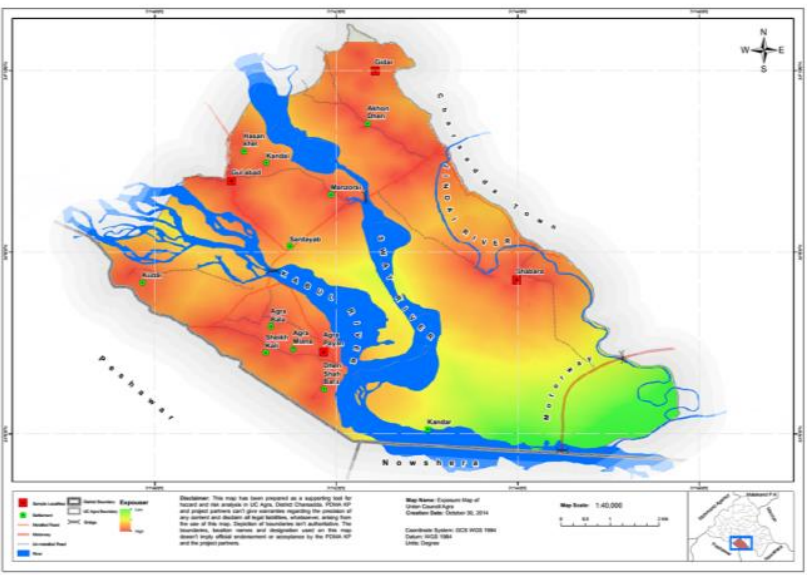

Figure 5. UC Agra-Exposure/ Vulnerability map

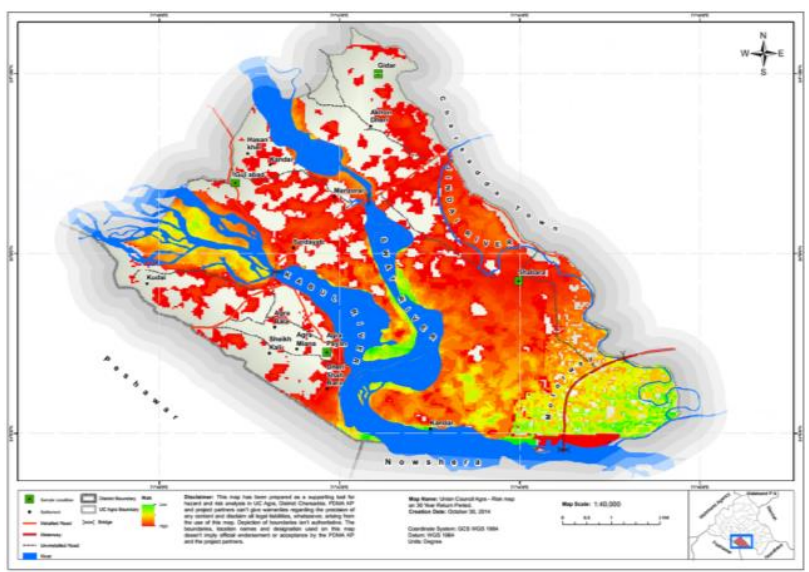

Figure 6. UC Agra- Risk map on 30-year return period

Total agricultural area in the study area was 6362 acres where 118 acres was at 30 years flood return periods, 2417 acres at risk to 30 years and 4707 acres of agriculture area was at risk to 100 years flood return period with high vulnerability ranking. The totals number of hospitals in the study area was 3 where two of them are at risk to 100 years return period with high

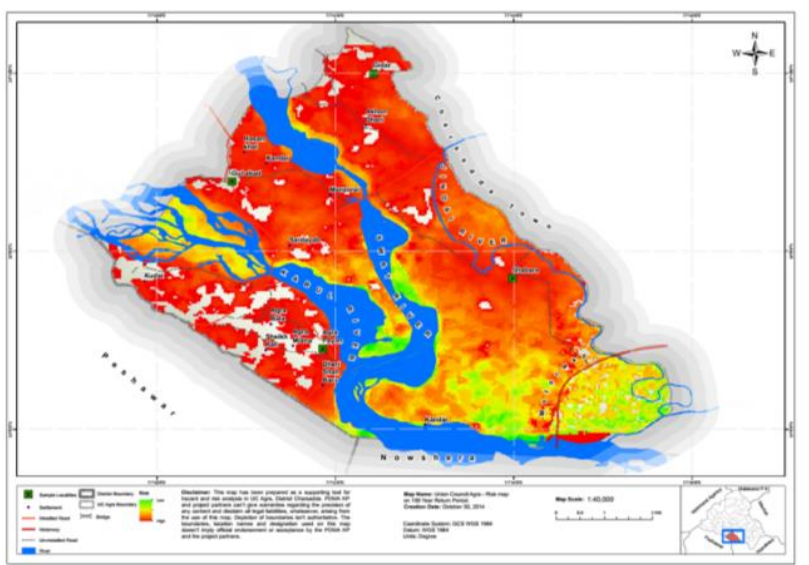

Figure 7. UC Agra- Risk map on 100-year return period

vulnerability index. Half of the total 25 schools are at risk to 100 years return period and only 8 schools are at risk to 30 years flood return period with high vulnerability index. The transportation networks are at high risk to flood risk.

\begin{tabular}{|l|l|}
\hline Village Level Risk Ranking & Rank \\
\hline Shabara & High \\
\hline Agra Payan & High \\
\hline Goder Kelay & High \\
\hline Dera Shabara & High \\
\hline Sheikh keley & High \\
\hline Gul Abad & High \\
\hline Agra Miana & High \\
\hline Kudi & High \\
\hline AgraBala & Moderate \\
\hline Manzorai & Moderate \\
\hline Hasan Kheil & Moderate \\
\hline Kandai & Low \\
\hline Akhondheri & Low \\
\hline
\end{tabular}

Table 2. Risk based ranking of villages in UC Agra

Total roads in the study area were 75 kilometers in which 15 kilometers roads are at risk to 10 years return period, 43 kilometers to 30 years return period and 67 kilometers are at high risk 100 years flood return period. The total hand pumps in the study area were 2398 in which 911 hand pumps are at risk to 30 years return period and 1774 are at high risk to 100 years return period however the contamination of underground water issue remains the same for all hand pumps. Total latrines in the study area were 3205 in which 1,217 are at risk to 30 years return period and 2,315 are at risk to 100 years flood return period 


\begin{tabular}{|c|c|c|c|c|}
\hline $\begin{array}{l}\text { Flood Hazard @ RP } \\
\text { Scenarios }\end{array}$ & Exposed Element & $\begin{array}{l}\text { Exposure } \\
\text { (Quantities) }\end{array}$ & $\begin{array}{l}\text { Vulnerability } \\
\text { Rank }\end{array}$ & Risk \\
\hline \multirow{8}{*}{$\begin{array}{c}<10 \text { Year Return period } \\
\text { Total inundated area }\end{array}$} & Population & 26,290 & Low & 0 \\
\hline & Buildings & 3,807 & Low & 0 \\
\hline & Crops/Vegetation & 6,362 Acre & High & 118 Acre \\
\hline & Schools & 25 & Low & 0 \\
\hline & Hospitals & 3 & Low & 0 \\
\hline & Roads & $75.7 \mathrm{~km}$ & High & $14.82 \mathrm{~km}$ \\
\hline & Hand Pumps & 2,398 & Moderate & 0 \\
\hline & Latrines & 3,205 & Low & 0 \\
\hline \multirow{8}{*}{$\begin{array}{c}\text { 30-100 Year Return } \\
\text { Period Total Inundated } \\
\text { Area }\end{array}$} & Population & 26,290 & Moderate & 8,724 \\
\hline & Buildings & 3,807 & Moderate & 1,446 \\
\hline & Crops/Vegetation & 6,362 Acre & High & 2,417 Acre \\
\hline & Schools & 25 & Low & 8 \\
\hline & Hospitals & 3 & High & 2 \\
\hline & Roads & $75.7 \mathrm{~km}$ & High & $43.15 \mathrm{~km}$ \\
\hline & Hand Pumps & 2,398 & Moderate & 911 \\
\hline & Latrines & 3,205 & High & 1,217 \\
\hline \multirow{8}{*}{$\begin{array}{l}100 \text { Year Return Period } \\
\text { Total Inundated Area }\end{array}$} & Population & 26,290 & High & 16,745 \\
\hline & Buildings & 3,807 & High & 2,817 \\
\hline & Crops/Vegetation & 6,362 Acre & Moderate & 4,707 acre \\
\hline & Schools & 25 & Moderate & 12 \\
\hline & Hospitals & 3 & High & 2 \\
\hline & Roads & $75.7 \mathrm{~km}$ & High & $66.7 \mathrm{~km}$ \\
\hline & Hand Pumps & 2,398 & High & 1,774 \\
\hline & Latrines & 3,205 & Moderate & 2,315 \\
\hline
\end{tabular}

Table 3. Risk profile of UC Agra, Charsadda

The Shabara village, Agra Payan, Gedar Kelay, Dera Shabara, Sheikh kelay, Gul Abad, Agra Miana and Kudi village of Union

Council Agra are at high risk to flood, while Agra Balan, Manzuri and Hasan Khel is at moderate risk to future flooding. Kandai and Akhon Derii villages are in low flood risk zone.

\section{CONCLUSION AND RECOMENDATIONS}

The study results revel that UC Agra is severely vulnerable to flood hazard by reason of its geographical location and lack of pre-disaster preparedness activities. Flood is a frequently (each year) occurring event in the UC Agra in monsoon season. The hazard intensity remains in between moderate to severe. Most of the houses are made of mud and bricks which cannot resist the overflowed water. Almost all sectors are of the UC are critical including housing, agriculture, health, roads, livestock, and education. The encouraging aspect of community is their cooperation in emergency situation. The Social networking amongst the community is quite strong and the people cooperate with each other in crisis. It is concluded from the findings that old people, disable persons, women, children are the vulnerable most people in the UC. Moreover, because of the lack of awareness regarding safety measures and improper information about the flood occurrences, people cannot help themselves effectively. Similarly, due to the lack of coordination between community and government agencies the developmental works are not yet initiated such as embankment along rivers, proper land use planning, weather forecasting, evacuation and relief actions, which could rise the damage many folds to the community. There is immense need of prevention and mitigation measure as floods are frequently occurring disaster in the area. Though flood is a regular disaster in the UC Agra but still there is no community leadership to guide the people regarding pre and post flood situation due to which every year people suffer a lot. The analysis of PRA data showed that the people of UC have the ability to minimize risk of flood if proper training be given to the residents.

Based on the study findings it is proposed that there is immense need of shelter places at village level with special DRR design, to ensure easy access, refuge with basic facilities. Furthermore, the results indicate that the UC Agra is facing high risk of flooding as a consequence of flow discharge obstacles due to narrow bridge of motorway, thus to solve this problem culverts are recommended to ease safe and judicious evacuation of the flood water. On the left side of Jindi River Shabara village is located and effected by flood when the water rises in the river. There is immense need to build disaster resilient embankments on Jindi River to secure village Shahbara. It was suggested during the study that on left side near Agra Payan, construction of spars and embankment are required to reduce the risk of flooding.

Some of the weak and vulnerable breaches require retrofitting and necessary repairing to stop further erosion and damages of the embankment wall. Plantation on both sides of the river bank will reduce the lateral erosion as it is one of main hazard for the 
UC Agra. Early warning system need to be installed which should link upstream communities with the downstream communities to ensure timely evacuation and early warning, that was felt lacking during the 2010flooding. UC and village level disaster management committees have been formed by various I/NGOs, which still exist. There is a need to enhance their capacities through hard and soft component. Digital record of the GIS based maps should be maintained with PDMA and District government as it will provide guidance and methodology on how to replicate this type of studies to other areas. It will also be helpful to update these maps at periodic intervals.

\section{REFERENCES}

Adeoye, N. O., Ayanlade. A., and Babatimehin. O., 2009. Climate change and menace of floods in Nigerian Cities: Socioeconomic implications. Advances in Natural and Applied Sciences.2009;3(3):369-77.

Ahmad. H., Bokhari. J. B., and Siddiqui. Q. T. M., 2011. Flashflood risk assessment in Pakistan. Pakistan Engineering Congress, 71st Annual Session Proceedings. 2011; Paper No.707:696-

708.

Alcántara-Ayala, I., O. Altan, D.N. Baker, S. Briceño, S.L. Cutter, H. Gupta, A. Holloway, A. Ismail-Zadeh, V. JiménezDíaz, D. Johnston, G.A. McBean, Y. Ogawa, D. Paton, E. Polio, R.K. Silbereisen, K. Takeuchi, G.B. Valsecchi, C. Vogel, G. Wu and P. Zhai., 2015. Disaster Risks research and assessment to promote risk reduction and management, ICSUISSC Ad-hoc Group on Disaster Risk Assessment, In: IsmailZadeh, A. and S.L. Cutter (eds.) ICSU-ISSC, 47 pp. (http://www.icsu.org/science-for-policy/disaster )

Haq, Ul. Ehsan., 2011. Community response to climate hazard in Northern Pakistan. Maintain Research and Development, 27 (4), 308-312.

Houze Jr, R. A., Rasmussen, K. L., Medina, S., Brodzik, S. R., and Romatschke, U., 2011. Anomalous atmospheric events leading to the summer 2010 floods in Pakistan. Bulletin of the American Meteorological Society, 92 (3), 291-298.

Hussain, I., Spock, G., Pilz, J., and Yu, H. L., 2010. SpatioTemporal interpolation of precipitation during monsoon periods in Pakistan. Advances in Water Resources, 33, 880886.

Khan, B., Iqbal, M.J. and Yousufzai, M.A.K. (2011). Flood Risk Assessment of River Indus of Pakistan. Arabian Journal of Geosciences, 4, 115-122.

NDMA., 2010. NDMA Annual Report. The Natural Disaster Management Authority. Government of Pakistan; 2010. Available at: www.ndma.gov.pk.

Ologunorisa TE, Abawua MJ (2005) Flood risk assessment: a review. App Sci Environ Mgt J 9(1):57-63

Osti, R., Tanaka, S., and Tokioka, T., 2008. Flood hazard mapping in developing countries: problems and prospects. Disaster Prevention and Management: An International Journal, 17(1), 104-113.

Riaz, S.,2012. Flood Hazard Assessment during Monsoon Floods of 2010: Case Study of Charsadda and Nowshera Districts. International Poster Journal of Science and Technology. 2012;1(1):7.

Simonovic, S. P., 2002. "Non-structural Measures for Water Management, Special Issue of Water International", Vol.27, No.1, page 40 .

WHO., 2011. Government of Pakistan, World Health Organization. Weekly Epidemiological Bulletin: Flood Response in Pakistan: Volume 2, Issue 4, Monday 25 July, 2011. 2011.

Revised August 2018 